\title{
Pharmacological closure of ductus arteriosus in preterm infants using indomethacin
}

\author{
H I OBEYESEKERE, S PANKHURST, AND V Y H YU
}

Department of Diagnostic Cardiology, and Department of Paediatrics, Queen Victoria Medical Centre, Melbourne, Victoria, Australia

SUMMARY Patent ductus arteriosus (PDA) was diagnosed in 27 (21\%) of 129 infants weighing $\gtrless 1500 \mathrm{~g}$ at birth presenting over $1 \frac{1}{2}$ years. The incidence of PDA in infants with pulmonary disease, particularly hyaline membrane disease, was higher than that in infants without such disease $(31 \%$ compared with 16\%). 16 (59\%) infants with PDA developed congestive cardiac failure (CCF), of whom 12 were $₹ 1000 \mathrm{~g}$ at birth. Eight of these infants had persistent CCF despite aggressive antifailure treatment, and 8 were ventilator-dependent although stable on medical management. Pharmacological ductal closure with indomethacin was attempted in these 16 infants according to clinical and echocardiographic criteria. Complete or partial ductal closure with clinical and echocardiographic improvement was achieved in $75 \%$ of infants. Treatment with indomethacin failed in 4 infants all of whom were $₹ 1000 \mathrm{~g}$ at birth and had gestational ages $₹ 26$ weeks. Two of these infants had surgical ligation of the PDA and recovered. No morbidity was attributed to indomethacin except for transient oliguria. Overall survival was $76 \%$; this ranged from $50 \%$ in infants weighing $501-750 \mathrm{~g}$, to $91 \%$ in infants weighing $1251-1500 \mathrm{~g}$.

Results suggest that (1) extremely preterm infants are less likely to respond to indomethacin, (2) success is more likely in the first 10 days of life, (3) a total dose greater than $0.6 \mathrm{mg} / \mathrm{kg}$ will not increase the success rate, (4) selective morbidity from indomethacin is unlikely if the contraindications of bleeding tendency, hyperbilirubinaemia, and renal dysfunction are followed, although urinary output must be monitored carefully, (5) indomethacin is a useful alternative to surgical ligation although long-term prognosis from clinical trials has yet to be established.

Improvement in neonatal intensive care has resulted in greater survival of preterm infants, and increased diagnosis of disorders associated with prematuritysuch as patent ductus arteriosus (PDA). Management of PDA has become one of the major problems in neonatal intensive care. ${ }^{1}$ For most preterm infants with PDA, conservative medical management is satisfactory. ${ }^{2-3}$ If cardiac or respiratory failure is progressive and life-threatening despite aggressive medical management, immediate ductal closure is essential for infant survival. ${ }^{4-6}$ Small preterm infants $₹ 1500 \mathrm{~g}$ with or without hyaline membrane disease (HMD) often have a prolonged course of ductus shunting and characteristically require weeks of mechanical ventilation. A recent study showed

Queen Victoria Medical Centre

Department of Diagnostic Cardiology

H I OBEYESEKERE, director

S PANKHURST, technician

Department of Paediatrics

V Y H YU, director of neonatal intensive care that early ductal closure led to earlier weaning from mechanical ventilation, decreased need for antifailure treatment, and earlier establishment of optimal nutrition via the enteric route. ${ }^{7}$ Friedman et al..$^{8}$ and Heymann et al..$^{9}$ have reported that inhibitors of prostaglandin synthesis (indomethacin and aspirin) are effective in closing the ductus.

Until June 1977, our management of infants with congestive cardiac failure (CCF) secondary to left-to-right shunting through a PDA was confined to conventional antifailure treatment using digoxin, frusemide, and respiratory support, and if this failed-surgical ligation. Between June 1977 and December 1978, indomethacin was used as an alternative to surgical ligation. If this failed surgery was used. This study reports the results of this trial.

\section{Patients and methods}

Study population. 129 infants $₹ 1500 \mathrm{~g}$ at birth were admitted between June 1977 and December 1978 to 
the neonatal unit of this centre. Their median birthweight was $1190 \mathrm{~g}$ (range 570-1500) and median gestational age 29 weeks (range 24-36). $39(30 \%)$ infants weighed between 501 and $1000 \mathrm{~g}$. Overall survival was $76 \% .16(52 \%)$ of the 31 deaths occurred earlier than 72 hours of age, before the presence of PDA could be evaluated.

General management. Details of neonatal intensive care methods and the protocol for ventilatory assistance have been described in previous reports. ${ }^{10-11}$ Parenteral nutrition was given before establishment of enteric feeds. Total daily fluid administered during the first week was 100-150 $\mathrm{ml} / \mathrm{kg}$, and increased to $150-200 \mathrm{ml} / \mathrm{kg}$ by the second week depending on the clinical and biochemical hydration state. Details of the parenteral nutrition regimen, the formulation used, and its administration and monitoring have been reported. ${ }^{12}$

Diagnosis of PDA. Essential features were a systolic murmur maximal at the left sternal edge or below the left clavicle, or a continuous murmur, with bounding pulses. When an arterial catheter was in situ the increased pulse pressure was measured directly. Serial chest $x$-rays, ECGs, and echocardiograms were performed. Infants were designated as having 'symptomatic PDA' (sPDA) when CCF secondary to a large left-to-right ductus shunt developed. The clinical signs included tachycardia $(>150 / \mathrm{min})$, gallop rhythm, hyperdynamic praecordium with collapsing pulses, moist râles in the chest on auscultation, and hepatomegaly. A deterioration of respiratory function was often heralded by increasing apnoeic episodes and bradycardia. Infants already on mechanical ventilation experienced increased oxygen and ventilatory requirements. $X$-ray findings included prominent pulmonary vasculature and evidence of pulmonary oedema, ranging from hazy lung fields to complete white-out ${ }^{13}$ and cardiomegaly. Serial echocardiography showed significant increases in left ventricular end-diastolic (LVED) and left atrial (LA) dimensions, and a left atrial/aortic (LA/Ao) ratio $>1 \cdot 2: 1$.

Management of PDA. Infants with PDA and no CCF were treated with careful regulation of the volume of fluid administered $(120 \mathrm{ml} / \mathrm{kg}$ per 24 hours). Infants who had CCF were treated with digoxin and frusemide. Fluids were restricted to $80-100 \mathrm{ml} / \mathrm{kg}$ per 24 hours. Digoxin $10 \mu \mathrm{g} / \mathrm{kg}$ IV was given initially followed by maintenance therapy 24 hours later of $5 \mu \mathrm{g} / \mathrm{kg}$ 12-hourly. Central haematocrit was maintained above $40 \%$ with transfusions of packed cells $10-15 \mathrm{ml} / \mathrm{kg}$ over 2 hours, followed by frusemide $1 \mathrm{mg} / \mathrm{kg}$.
Indomethacin therapy. If, despite medical management, cardiac failure persisted or ventilatory requirement increased, indomethacin was administered. The initial dose of indomethacin was $0 \cdot 3$ $\mathrm{mg} / \mathrm{kg}$ and this was repeated 24 hours later if the PDA murmur persisted. The course was repeated later if signs recurred. Because of drug insolubility, indomethacin was suspended in syrup BP and water vehicle $(0.2 \mathrm{mg} / \mathrm{ml})$ and given via a gastric tube. $\mathrm{Hb}$, haematocrit, white blood count, platelet count, serum indirect bilirubin, stool guaiacum reaction, blood urea, and urine analysis were performed. Blood-gases and serum electrolytes were monitored routinely. Fluid intake, urinary output, and body weight were recorded daily. Serial chest $x$-rays, ECGs, and echocardiograms were performed. Contraindications to the use of indomethacin included bleeding tendency, necrotising enterocolitis, serum indirect bilirubin $>150 \mu \mathrm{mol} / 1(8.8 \mathrm{mg} / 100$ $\mathrm{ml})$, and blood urea $>8 \mathrm{mmol} / 1(48 \cdot 2 \mathrm{mg} / 100 \mathrm{ml})$.

\section{Results}

Incidence. PDA was diagnosed in 27 (21\%) of 129 infants $₹ 1500 \mathrm{~g}$ at birth. The incidence of PDA was higher in infants with lower birthweights: $16(41 \%)$ infants weighing 501-1000 g compared with 11 $(12 \%)$ in infants weighing $1001-1500 \mathrm{~g}$. Birthweights and gestational ages of infants with and without PDA are given in Table $1.59(46 \%)$ infants had HMD. PDA was present in $16(27 \%)$ of 59 infants with HMD compared with $11(16 \%)$ of 70 without HMD. In addition, 2 infants with intrapartum pneumonia (group B $\beta$-haemolytic streptoccal infection) and one infant with WilsonMikity syndrome had PDA. The incidence of PDA in infants with pulmonary disease $(31 \%)$ was higher than that in the infants without $(16 \%)\left(\chi^{2}=5 \cdot 72\right.$, $\mathbf{P}<0.05)$. The PDA murmur was first heard between 4 and 14 days after birth (median 6); 18 $(67 \%)$ by the end of the first week, and $9(33 \%)$ in the course of the second week.

Table 1 Birthweights and gestations of infants weighing $₹ 1500 \mathrm{~g}$ with and without $P D A$

\begin{tabular}{llll}
\hline & \multicolumn{1}{l}{ Infants } & & $\begin{array}{l}\text { All } \\
\text { infants } \\
(n=129)\end{array}$ \\
\cline { 2 - 3 } & $\begin{array}{l}\text { With PDA } \\
(n=27)\end{array}$ & $\begin{array}{l}\text { Without PDA } \\
(n=102)\end{array}$ & \\
\hline $\begin{array}{l}\text { Gestation } \\
\text { Mean }\end{array}$ & 28 & 29 & 29 \\
Median & 27 & 29 & 29 \\
$\begin{array}{l}\text { Range } \\
\text { Birthweight }\end{array}$ & $24-33$ & $24-36$ & $24-36$ \\
Mean & 1020 & 1180 & 1150 \\
Median & 940 & 1220 & 1190 \\
Range & $620-1400$ & $570-1500$ & $570-1500$ \\
\hline
\end{tabular}


Symptomatic PDA. 11 (41\%) of the 27 infants with PDA had an uneventful course, uncomplicated by CCF or ventilator dependence, followed by spontaneous ductal closure. The remaining $16(59 \%)$ developed CCF, 12 of whom weighed 501-1000 g. They fell into four clinical groups: (1) Three (19\%) infants without respiratory disease developed PDA, $\mathrm{CCF}$, and continued to deteriorate despite antifailure treatment and ventilation. (2) Two (12\%) infants with HMD who after a few days of gradual improvement of their respiratory distress deteriorated after the appearance of PDA and CCF despite antifailure treatment, increased oxygen and ventilation. (3) Three (19\%) with HMD or pneumonia developed PDA and CCF during the course of ventilatory treatment and continued to deteriorate despite antifailure treatment. (4) Eight (50\%) infants with HMD developed PDA and CCF during the course of ventilatory therapy and, although stable on antifailure treatment, were ventilator-dependent.

Indomethacin therapy. The 16 infants with sPDA who had persistent CCF or were ventilator-dependent despite antifailure treatment were treated with indomethacin. Their median birthweight was $840 \mathrm{~g}$ (range 620-1340) and median gestational age 26 weeks (range 24-28). 12 of the infants weighed $₹ 1000$ g. The first dose of indomethacin was administered between 8 and 22 days (median 10). Only 6 of 16 infants received the first dose before 10 days of age.

After the administration of indomethacin the time taken for clinical and echocardiographic evidence of ductal closure varied as did the number of doses needed to achieve this. Ductal closure with complete disappearance of both the PDA murmur and signs of CCF with return of echocardiogram to normal occurred in $9(56 \%)$ infants. This was achieved within 24 hours of a single dose in 4 infants, and after a course of two doses in 5 infants. The murmur became softer and there was pronounced clinical and echocardiographic improvement in a further 3 $(19 \%)$ infants. Four $(25 \%)$ infants failed to respond to indomethacin despite two courses of treatment in 3 infants and three courses of treatment in the other. Two of these infants (birthweights 780 and $820 \mathrm{~g}$ ) underwent surgical ligation of the ductus and recovered. The other 2 infants (birthweights 720 and $980 \mathrm{~g}$ ) remained critical on respiratory treatment and subsequently died of intraventricular haemorrhage in the third week after birth, 8 and 10 days respectively after treatment with indomethacin. The PDA murmur recurred with evidence of a left-toright shunt in 3 of the 8 infants whose ducts closed after the first course. This coincided with acute hypoxaemia due to blockage of the endotracheal tube in one instance, increasing respiratory distress from pneumonia in another, and inadvertent sudden increase in the parenteral fluid infusion rate in the third. The effects of indomethacin on LVED and LA dimensions and the LA/Ao ratio are shown in Figs 1 to 3.

Morbidity and mortality. Urinary output fell in several infants receiving indomethacin after the first dose; 24 to 48 hours after the last dose, urine

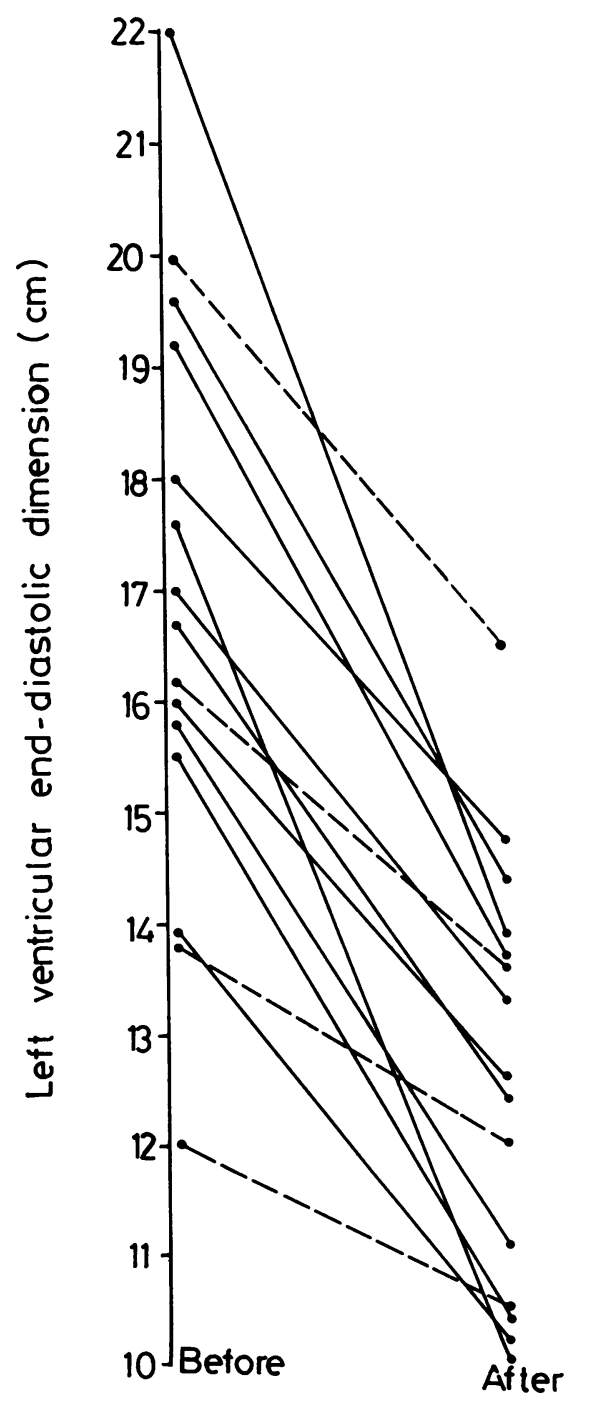

Fig. 1 Left ventricular end-diastolic dimension before and after treatment with indomethacin. 


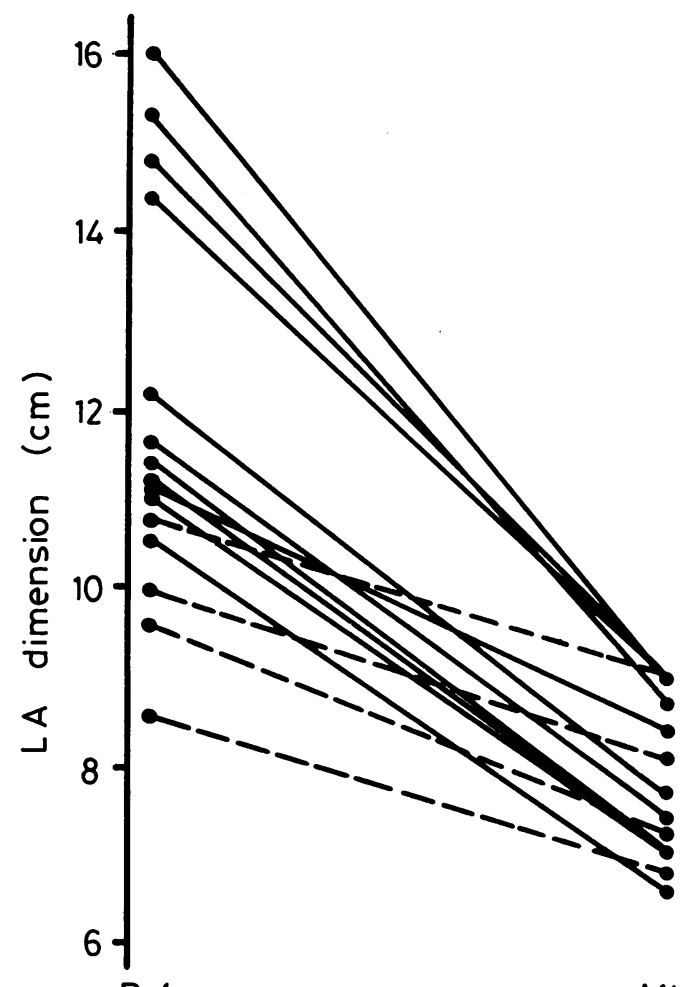

Before

After

Fig. 2 Left atrial dimension before and after treatment with indomethacin.

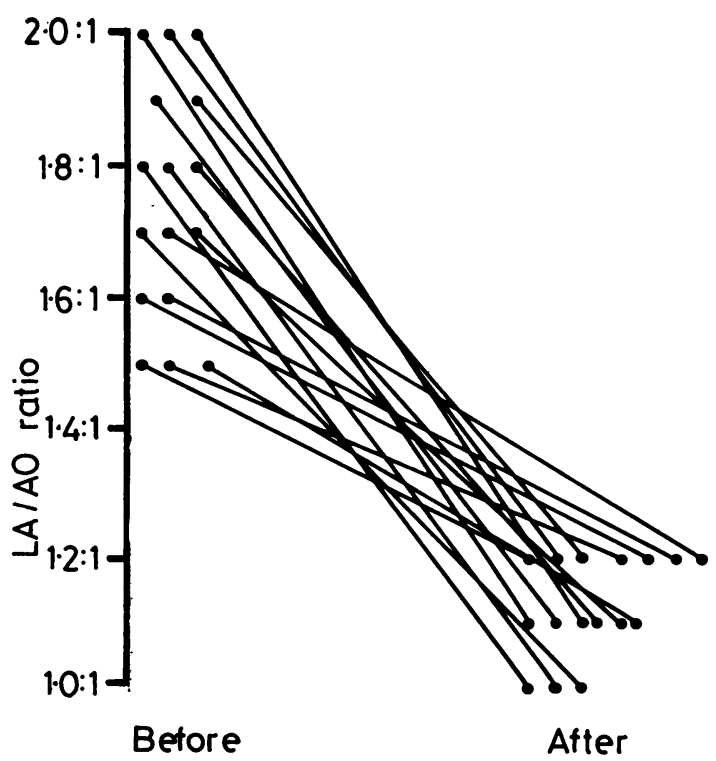

Fig. 3 Left atrial/aortic ratio before and after reatment with indomethacin.
Table 2 Survival rates of infants weighing $<1500 \mathrm{~g}$ with and without $P D A$

\begin{tabular}{|c|c|c|c|c|c|c|}
\hline \multirow[t]{3}{*}{ Birthweight (g) } & \multicolumn{4}{|c|}{ No. of infants } & \multicolumn{2}{|c|}{ Total survivors } \\
\hline & \multicolumn{2}{|c|}{ With PDA } & \multicolumn{2}{|c|}{ Without PDA } & \multirow[b]{2}{*}{ No. } & \multirow[b]{2}{*}{$\%$} \\
\hline & Survived & Died & Survived & Died & & \\
\hline $\begin{array}{l}501-750(n=10) \\
751-1000(n=29) \\
1001-1250(n=37) \\
1251-1500(n=53) \\
\text { Total }(n=129)\end{array}$ & $\begin{array}{l}2 \\
9 \\
3 \\
8 \\
22(81 \%)\end{array}$ & $\begin{array}{l}3 \\
2 \\
0 \\
0\end{array}$ & $\begin{array}{l}3 \\
10 \\
23 \\
40 \\
76(75 \%)\end{array}$ & $\begin{array}{l}2 \\
8 \\
11 \\
5 \\
9\end{array}$ & $\begin{array}{l}5 \\
19 \\
26 \\
48 \\
98\end{array}$ & $\begin{array}{l}50 \\
66 \\
70 \\
91 \\
76\end{array}$ \\
\hline
\end{tabular}

flow returned to normal. Throughout the episodes of oliguria, serum electrolytes remained normal and excessive weight gain was prevented by appropriate restriction of fluid intake. No other complications of indomethacin administration were observed.

$11(9 \%)$ of the 129 infants $₹ 1500 \mathrm{~g}$ developed bronchopulmonary dysplasia (BPD) of whom 10 were $₹ 1000 \mathrm{~g}$ at birth. Eight $(30 \%)$ of the 27 infants who had PDA developed BPD, the ductus in these cases remained patent for up to 8 to 20 days of age. Only $3(3 \%)$ of 102 infants without PDA developed BPD. This association between PDA and subsequent development of BPD is significant $\left(\chi^{2}=16 \cdot 2\right.$, $\mathrm{P}<0.001$ ).

Overall survival in this series was $76 \%$ (Table 2). Survival rates ranged from $50 \%$ in infants weighing 501 to $750 \mathrm{~g}$, to $91 \%$ in the 751 to $1000 \mathrm{~g}$ weight group.

\section{Discussion}

Previous reports of PDA in preterm infants have ranged from 15 to $36 \%$ depending on the degree of prematurity, frequency of HMD, and incidence of early neonatal mortality. ${ }^{1314-15}$ This compares with a $21 \%$ incidence of PDA reported in the present series of preterm infants $₹ 1500 \mathrm{~g}$, with a higher incidence of $41 \%$ in infants $501-1000 \mathrm{~g}$. In addition the incidence of PDA was significantly higher in infants with pulmonary disease, primarily HMD, compared with those without, as has been reported earlier. ${ }^{1-2}$

Evaluating the magnitude of left-to-right shunts in preterm infants with PDA is of fundamental importance in their management. Since cardiac catheterisation may be a considerable risk to these seriously ill infants, a simple noninvasive method is invaluable. Silverman et al. ${ }^{16}$ described the echocardiographic measurement of the LA/Ao ratio as a valuable index of the size of left-to-right ductal shunts. However there are reports of infants with substantial left-to-right shunting across a PDA in whom absolute LA dimensions and LA/Ao ratios were within normal limits. ${ }^{17}$ In these reports the 
LVED was more reliable. To avoid these pitfalls we performed serial echocardiography on these infants and used significant increases in LA/Ao ratio, LA and LVED dimensions in our echocardiographic evaluation. An LA/Ao ratio over 1 $2: 1$ signified heart failure and a ratio of $1 \cdot 5: 1$ was a critical value signifying the need to attempt closure of the ductus. Graphs previously obtained from 25 normal preterm infants served as normograms for LA and LVED dimensions. Serial echocardiographic assessment thus provided objective criteria which helped to determine the magnitude of $\mathbf{L}-\mathrm{R}$ shunting and decide when ductal closure was required for the infant to survive.

Complete pharmacological closure of sPDA was achieved in $56 \%$ of preterm infants treated, and partial closure with reduced left-to-right shunting and clinical and echocardiographic improvement in a further $19 \%$. Indomethacin failed to produce constriction in $25 \%$. Heymann et al. $^{9}$ reported success in over $90 \%$ of preterm infants treated. In their series only 5 out of 15 infants weighed $₹ 1000 \mathrm{~g}$ and most had gestational ages over 28 weeks. Merritt et al. ${ }^{4}$ reported success in $32(91 \%)$ out of 35 infants. In their study $9(26 \%)$ infants had birthweights over $1500 \mathrm{~g}$, and only $10(29 \%)$ were $<1000$ g. The morbidity and mortality rate related to PDA in infants weighing $>1500 \mathrm{~g}$ is slight and such babies rarely pose a problem in management. In the present series, $12(75 \%)$ of the 16 infants treated with indomethacin were $<1000 \mathrm{~g}$, all of whom had gestational ages between 24 and 28 weeks. All 4 infants who did not respond to indomethacin had gestational ages between 24 and 26 weeks and weighed $₹ 1000 \mathrm{~g}$ (range 720-980). Heymann et al. ${ }^{9}$ had one failure out of 5 infants weighing $₹ 1000 \mathrm{~g}$ when given indomethacin. It would therefore appear that while indomethacin is successful in constricting the PDA in preterm infants weighing $>1000 \mathrm{~g}$ with gestational ages $>28$ weeks, it is less successful in more immature infants weighing $₹ 1000$ g. Neal et al. ${ }^{14}$ have reported an $80 \%$ failure rate in preterm infants with HMD and PDA which they attributed to administering the drug after 10 days of age. In our series too, only 6 out of 16 infants were given the drug under 10 days. This was due to CCF being treated first with antifailure treatment and indomethacin administered only if this failed. Of the 4 infants who failed to respond to indomethacin, only one had it earlier than 10 days. This too may have contributed to the $25 \%$ failure rate (4 infants).

The association between PDA and the subsequent development of BDP in this study was striking. Three main factors have been implicated in the pathogenesis of BPD: barotrauma from mechanical ventilation, ${ }^{18}$ oxygen toxicity, ${ }^{19}$ and CCF secondary to left-to-right shunting through a PDA. ${ }^{20}$ Gay et al. showed that PDA and large left-to-right shunts over 2 days increased the risk of developing BPD. ${ }^{20}$ Early ductal closure may shorten the duration of ventilatory assistance and thereby reduce the risk of BPD, besides increasing the chances of successful pharmacological closure.

Several principles have emerged from the experience in this and other recent studies with indomethacin in sPDA. (1) Extremely preterm infants are less likely to respond to indomethacin. (2) Success is more likely if the drug is administered early, before 10 days of age. (3) Dosage of $0.3 \mathrm{mg} / \mathrm{kg}$ repeated in 24 hours is safe and causes no untoward side effects. (4) Increasing dosage will not increase success rate. (5) Bleeding tendency, hyperbilirubinaemia, and renal dysfunction are contraindications to its use. (6) Urinary output must be carefully monitored. (7) Long-term prognosis is still to be ascertained after clinical trials with this drug. (8) Indomethacin is effective in closing the ductus and a useful alternative to surgical ligation. (9) If it fails surgery should follow.

\section{References}

1 Siassi B, Blanco C, Cabal L A, Coran A G. Incidence and clinical features of patent ductus arteriosus in low birthweight infants: a prospective analysis of 150 consecutively born infants. Pediatrics 1976; 57: 347-51.

2 Cotton R B, Stahlman M T, Kovar I, Catterton W Z. Medical management of small preterm infants with symptomatic patent ductus arteriosus. J Pediatr 1978; 92 : 467-73.

3 Jones R W A, Pickering D. Persistent ductus arteriosus complicating the respiratory distress syndrome. Arch Dis Child 1977; 52: 274-81.

4 Merritt T A, Disessa T G, Feldman B H, Kirkpatrick S E, Gluck L, Friedman W F. Closure of patent ductus arteriosus with ligation and indomethacin: consecutive experience. J Pediatr 1978; 93: 639-46.

5 Cooke R W I, Gribbin B, Gunning A J, Pickering D. Ligation of patent ductus arteriosus in the very low birthweight newborn infant. Arch Dis Child 1978; 53: 271-5.

- Nadas A S. Patent ductus revisited. $N$ Engl J Med 1976; 295: 563-5.

7 Cotton R B, Stahlman M T, Bender H W, Graham T P, Catterton W Z, Kovar I. Randomized trial of early closure of symptomatic patent ductus arteriosus in small preterm infants. J Pediatr 1978; 93: 647-51.

8 Friedman W F, Hirschklau M J, Printz M P, Pitlick P T, Kirkpatrick S E. Pharmacologic closure of patent ductus arteriosus in the premature infant. $N$ Engl J Med 1976; 295: 526-9.

9 Heymann M A, Rudolph A M, Silverman N H. Closure of the ductus arteriosus in premature infants by inhibition of prostaglandin synthesis. $N$ Engl J Med 1976; 295: 530-3.

10 Yu V Y H, Hollingsworth E. Improving prognosis for infants weighing $1000 \mathrm{~g}$ or less at birth. Arch Dis Child $1980 ; 55$ : in press.

$11 \mathrm{Yu} \mathrm{V} \mathrm{Y} \mathrm{H,} \mathrm{Hollingsworth} \mathrm{E.} \mathrm{Respiratory} \mathrm{failure} \mathrm{in}$ infants weighing $1000 \mathrm{~g}$ or less at birth. Aust Paediatr $J$ 1979; 15: 152-9. 
12 Yu V Y H, James B, Hendry P, MacMahon R A. Total parenteral nutrition in very low birthweight infants: a controlled trial. Arch Dis Child 1979; 54: 653-61.

13 Wesenberg R L, Wax R E, Zachman R D. Varying roentgenographic patterns of patent ductus arteriosus in the newborn. AJR 1972;114: 340-9.

14 Neal W A, Kyle J M, Mullett M D. Failure of indomethacin therapy to induce closure of patent ductus arteriosus in premature infants with respiratory distress syndrome. J Pediatr 1977; 91 : 621-3.

15 Kitterman J A, Edmunds L H, Jr, Gregory G A, Heymann M A, Tooley W H, Rudolph A M. Patent ductus arteriosus in premature infants: incidence, relation to pulmonary disease, and management. $N$ Engl J Med 1972; 287: 473-7.

16 Silverman N H, Lewis A B, Heymann M A, Rudolph A M. Echocardiographic assessment of ductus arteriosus shunt in premature infants. Circulation 1974; 50: 821-5.

17 Hirschklau M J, Disessa T G, Higgins C B, Friedman W F. Echocardiographic diagnosis: pitfalls in the premature infant with a large patent ductus arteriosus. $J$ Pediatr 1978; 92: 474-7.

18 Taghizadeh A, Reynolds E O R. Pathogenesis of bronchopulmonary dysplasia following hyaline membrane disease. Am J Pathol 1976; 82: 241-64.

19 Edwards D K, Wayne M D, Northway W H, Jr. Twelve years' experience with bronchopulmonary dysplasia. Pediatrics 1977; 59: 839-46.

20 Gay J H, Daily W J R, Meyer B H P, Trump D S, Cloud D T, Molthan M E. Ligation of the patent ductus arteriosus in premature infants: report of 45 cases. $J$ Pediatr Surg 1973; 8: 677-83.

Correspondence to Dr V Y H Yu, Department of Paediatrics, Queen Victoria Medical Centre, 172 Lonsdale Street, Melbourne 3000, Australia.

Received 20 March 1979 